\title{
Polyanions in syphilis: Evidence that glycoproteins and macromolecules resembling glycosaminoglycans are synthesised by host tissues in response to infection with Treponema pallidum
}

\author{
R A STRUGNELL, * C J HANDLEY,† L DRUMMOND,* S FAINE,* \\ D A LOWTHER, + AND S R GRAVES*
}

From the Departments of *Microbiology and + Biochemistry, Monash University, Clayton, Victoria, Australia

SUMMARY We investigated by means of radiolabelled precursors the source and nature of the polyanionic macromolecules present in rabbit tissues during active syphilis infection. Previous studies indicated that Treponema pallidum itself does not synthesise glycosaminoglycans, at least in vitro. In replicate experiments on unilaterally infected rabbits, tissue from the orchitic testis incorporated two to three times more ${ }^{35} \mathrm{~S}$-sulphate and ${ }^{3} \mathrm{H}$-glucosamine (on a wet weight basis) than tissue from the non-orchitic contralateral testis. Incorporation of ${ }^{35} \mathrm{~S}$-sulphate was independent of the number of viable $T$ pallidum organisms present in the infected tissue, which suggested that incorporation represented biosynthesis by the host and not the treponeme. Testes from syphilitic rabbits two days after treatment with high doses $(100 \mathrm{mg} / \mathrm{kg})$ of penicillin incorporated less ${ }^{35} \mathrm{~S}$-sulphate than untreated infected testes, but more than normal uninfected rabbit testes. This suggests that active syphilitic infection was necessary for maximum biosynthesis of the macromolecule(s) by host tissue.

Hydrodynamic profiles showed incorporation of radiolabelled precursors into two distinct fractions of different sizes, which may represent a proteoglycan and a sulphated glycoprotein. Alcian blue staining of syphilitic testes at or after peak orchitis showed focal deposition of newly synthesised polyanionic components during peak orchitis and a more generalised fibrosis in testes after peak orchitis.

\section{Introduction}

Early studies of experimental syphilis lesions showed metachromasia after staining with the cationic dye, toluidine blue. ${ }^{2}$ This metachromasia was corrected by treatment with testicular hyaluronidase, which suggested that the staining reaction may have been due to the accumulation of large, polyanionic glycosaminoglycans. ${ }^{3}$ More recently, glycosaminoglycans or chemically similar polyanions have been found in the serum of syphilitic rabbits, ${ }^{4}$ and in the mucoid material produced during syphilitic orchitis. ${ }^{45}$ The origin and function of these polyanions is not known, but they may have important roles in the pathogenesis of syphilis. ${ }^{6}$ The

Address for reprints: R Strugnell, Department of Microbiology, Monash University Medical School, Alfred Hospital, Prahan, Victoria, Australia 3181

Accepted for publication 19 October 1983 mucoid material which accumulates during syphilitic orchitis appears to be immunosuppressive as transfer of this material into syphilitic rabbits reactivated dermal lesions which were healing, ${ }^{7}$ and extracts from syphilitic rabbit testes containing a mucoid substance inhibited in vitro transformation of rabbit lymphocytes. ${ }^{8}$

Polyanionic material has been seen on the surface of Treponema pallidum by electron microscopy, 910 and this outer layer may protect the organism from the host immune response, ${ }^{9}$ or from oxygen toxicity. ${ }^{6}$ Although early studies suggested that $T$ pallidum synthesised a capsule containing glycosaminoglycans and that dissipation of this capsule yielded the metachromasia seen during syphilitic infection, ${ }^{11}$ we have shown that $T$ pallidum does not synthesise glycosaminoglycans in vitro. ${ }^{12}$ It is possible, however, that $T$ pallidum might synthesise these molecules in vivo. Alternatively, glycosaminoglycans synthesised by the host may adhere to the surface of 
$T$ pallidum as other macromolecules derived from the host associate readily with the treponeme. ${ }^{13}$

This study investigated the source and nature of polyanionic macromolecules produced during syphilitic infection of rabbits.

\section{Materials and methods}

Stocks of $T$ pallidum (Nichols strain) were maintained by testicular passage in sexually mature rabbits and by freezing in $15 \%$ glycerol stored at $-70^{\circ} \mathrm{C}$. The medium used throughout the study was Eagle's minimal essential medium (Flow Laboratories, Melbourne, Australia) containing $10 \%$ fetal calf serum (Flow), $1 \mathrm{mmol} / 1$ dithiothreitol (Sigma Chemical Co, St Louis, United States), and $5 \mathrm{mmol} / \mathrm{l}$ N-2-Hydroxyethyl-piperazine- $\mathrm{N}^{\prime}$-2-ethanesulphonic acid (HEPES) (Flow).

\section{INCORPORATION OF RADIOLABELLED PRECURSORS INTO ORCHITIC AND NON- ORCHITIC SYPHILITIC RABBIT TESTES}

Sexually mature rabbits were infected in only one testis with $50 \times 10^{6} T$ pallidum organisms. When unilateral orchitis developed 8-10 days later the rabbits were killed and both testes removed aseptically. Portions of about $\mathbf{2 0 0} \mathrm{mg}$ wet weight of testis were placed in weighed tubes containing $2 \mathrm{ml}$ of medium. After weighing the tubes again to determine the mass of the tissue, each slice of testis was radiolabelled with either $20 \mu \mathrm{Ci} / \mathrm{ml}^{3} \mathrm{H}$-glucosamine (20-40 $\mathrm{Ci} / \mathrm{mmol}$, Amersham International, Amersham, United Kingdom) or $20 \mu \mathrm{Ci} / \mathrm{ml}{ }^{35} \mathrm{~S}$-sulphate ( $5 \mathrm{mCi} / \mu \mathrm{g} \mathrm{S}$, Amersham). The tissue slices were incubated with the labelled precursors for 24 hours at $34^{\circ} \mathrm{C}$ whereafter an equal volume of $8 \mathrm{~mol} / \mathrm{l}$ guanidine hydrochloride containing protease and testicular hyaluronidase inhibitors was added, ${ }^{12}$ to yield a final concentration of $4 \mathrm{~mol} / \mathrm{l}$ guanidine hydrochloride. Extraction was carried out at $4^{\circ} \mathrm{C}$ for 24 hours after which the samples were centrifuged at $1000 \times g$ for 10 minutes. The supernatant (guanidine extract) was collected and stored at $-20^{\circ} \mathrm{C}$. The pellet containing non-solubilised tissue was resuspended in papain digest buffer $(5 \mathrm{mmol} / \mathrm{l}$ cysteine hydrochloric acid and $5 \mathrm{mmol} / 1$ ethylenediamine-tetraacetic acid, both from Sigma) containing $2 \mathrm{~g} / \mathrm{l}$ papain (type IV, Sigma) and digested at $60^{\circ} \mathrm{C}$. After eight hours $2 \mathrm{~g} / 1$ fresh papain was added and digestion continued for a further 12 hours, when the digest (papain digest) was collected and stored at $-20^{\circ} \mathrm{C}$.

\section{GEL FILTRATION OF RADIOLABELLED} MACROMOLECULES

Guanidine extracts of infected rabbit testes labelled with ${ }^{3} \mathrm{H}$-glucosamine and ${ }^{35} \mathrm{~S}$-sulphate and normal rabbit testes were fractionated on Sepharose CL-6B. The extracts were dialysed against $4 \mathrm{~mol} / \mathrm{l}$ guanidine hydrochloride to remove excess free radiolabelled precursor, and a $1 \mathrm{ml}$ sample was fractionated on a Sepharose CL-6B column $(1 \times 90 \mathrm{~cm})$, equilibrated, and eluted at a flow rate of $6 \mathrm{ml} /$ hour with a buffer containing $4 \mathrm{~mol} / 1$ guanidine hydrochloride, $0.1 \mathrm{~mol} / 1$ sodium sulphate, $0.05 \mathrm{~mol} / 1$ sodium acetate, and $0 \cdot 1 \%$ Triton $\mathrm{X}-100$ at $\mathrm{pH} 5 \cdot 8$. Fractions of $1.2 \mathrm{ml}$ were collected and assayed for radioactivity.

Guanidine extracts of normal and infected testes were also fractionated on a Sepharose CL-6B column $(1.5 \times 60 \mathrm{~cm})$, equilibrated, and eluted with $0.2 \mathrm{~mol} / 1$ pyridine-acetic acid buffer at $\mathrm{pH} 6.5$ using a flow rate of $6 \mathrm{ml} /$ hour. Fractions of $2 \mathrm{ml}$ were collected and assayed for hexuronic acid by the method of Bitter and Muir. ${ }^{14}$

TREATMENT IN VITRO OF INFECTED RABBIT TESTES WITH PENICILLIN BEFORE LABELLING WITH ${ }^{35}$ S-SULPHATE

Slices of testes from rabbits at peak orchitis 8-10 days after intratesticular infection with $50 \times 10^{6}$ treponemes were placed in weighed tubes containing $2 \mathrm{ml}$ of medium with or without $1000 \mathrm{U} / \mathrm{ml}$ benzyl penicillin (Crystapen, Glaxo, Melbourne, Australia). At $0,30,60,120$, and 300 minutes the incubation medium was removed and replaced with $2 \mathrm{ml}$ of fresh medium containing $20 \mu \mathrm{Ci} / \mathrm{ml}{ }^{35} \mathrm{~S}$-sulphate (Amersham). After 24 hours in the presence of radiolabel, the tissue was extracted in an equal volume of $8 \mathrm{~mol} / \mathrm{l}$ guanidine hydrochloride for 24 hours at $4^{\circ} \mathrm{C}$. The incubation medium removed from untreated tissue or that treated with penicillin was immediately inoculated into the shaved backs of rabbits to assess the approximate number of viable $T$ pallidum organisms present in each sample. ${ }^{15}$ Three sites per sample were injected intradermally with $0.1 \mathrm{ml}$ of medium, and the rabbits were observed daily for the development of indurated lesions. The latent period of these lesions was defined as the number of days the inoculated sites took to become indurated.

TREATMENT IN VIVO OF INFECTED RABBITS WITH PENICILLIN

Four rabbits were each infected unilaterally with $50 \times 10^{6} T$ pallidum organisms. Eight days after infection, two rabbits were injected with $100 \mathrm{mg} / \mathrm{kg}$ benzyl penicillin (Crystapen, Glaxo) intramuscularly. Two days later (10 days after infection) the treated and the untreated rabbits were killed, and slices of both the orchitic and the non-orchitic testis from each rabbit were labelled with ${ }^{35} \mathrm{~S}$-sulphate and extracted in $4 \mathrm{~mol} / 1$ guanidine hydrochloride. 
Samples of tissue were also removed for staining with alcian blue (see below).

MEASUREMENT OF RADIOLABEL INCORPORATED INTO MACROMOLECULES

The method of Stevens et al was used to measure the amount of incorporation of radiolabelled precursors into macromolecules. ${ }^{16}$ Samples of $200 \mu$ l of the guanidine extracts or papain digests were fractionated by gel filtration on Sephadex G-25 using PD-10 columns (Pharmacia, Uppsala, Sweden) and equilibrated with $4 \mathrm{~mol} / \mathrm{l}$ guanidine hydrochloride, $0.1 \mathrm{~mol} / 1$ sodium sulphate, $0.05 \mathrm{~mol} / 1$ sodium acetate, and $0 \cdot 1 \%$ Triton X-100 (Sigma) pH 5.8. The macromolecular fractions were collected and counted in a scintillation mixture containing $50 \%$ (v/v) Triton X-100, 50\% toluene, and $0.8 \% 2,5-$ diphenyloxazole.

\section{STAINING OF INFECTED RABBIT TESTES WITH}

ALCIAN BLUE

Small ( $5 \mathrm{~mm}$ by $10 \mathrm{~mm}$ ) pieces of normal rabbit testes, syphilitic rabbit testes at peak orchitis, testes 3-5 days after peak orchitis, and orchitic and nonorchitic testes from rabbits treated in vivo with penicillin (see above) were fixed in buffered formalin and embedded in paraffin. Sections $8 \mu \mathrm{m}$ thick from each were hydrated in the usual manner, rinsed in distilled water, and stained with $1 \%$ alcian blue (ICI Chemicals, Melbourne, Australia) in 3\% (v/v) acetic acid for 30 minutes, washed in water, and counterstained in $1 \%$ neutral red (BDH, Melbourne) for 3 minutes. The sections were washed in water, dehydrated, cleared, and mounted in dibutylpthalate polystyrene xylol (DPX). ${ }^{17}$ They were silver stained by the modified method of Levaditi. ${ }^{17}$

TABLE I Incorporation of $\mathrm{Na}_{2}{ }^{35} \mathrm{SO}_{4}$ by orchitic and nonorchitic testes from syphilitic rabbits. (No (\%) disintegrations per minute/mg wet weight)

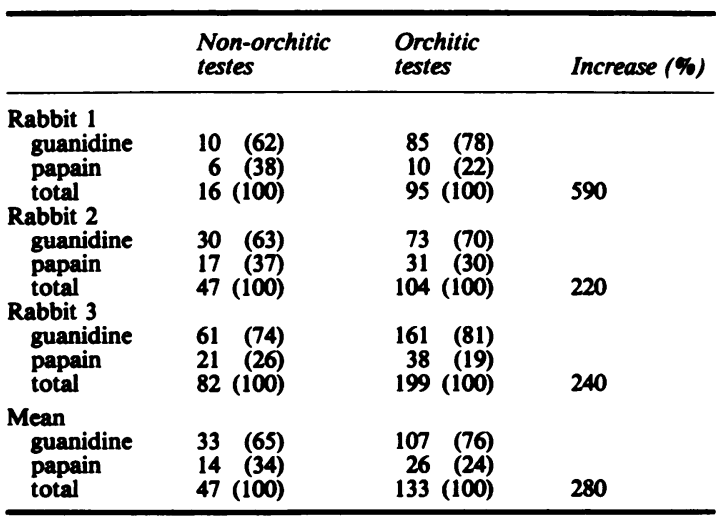

Results

INCORPORATION OF RADIOLABELS INTO MACROMOLECULES BY ORCHITIC AND NONORCHITIC TESTES FROM SYPHILITIC RABBITS

Three rabbits were each infected in one testis only so that unilateral orchitis developed. Incorporation of ${ }^{35} \mathrm{~S}$-sulphate and ${ }^{3} \mathrm{H}$-glucosamine ${ }^{18}$ into macromolecules was compared in the orchitic testis and the non-orchitic testis removed from the same rabbit. The results for ${ }^{35} \mathrm{~S}$-sulphate incorporation are shown in table $I$. On a wet weight basis, orchitic testes incorporated $2 \cdot 2$ to 5.9 times (mean 2.8) more ${ }^{35} \mathrm{~S}$-sulphate than non-orchitic testes from the same rabbits. Most of the incorporated label for both the non-orchitic and orchitic testes was present in the guanidine extracts.

Table II shows that orchitic testes incorporated $1 \cdot 6$ to 2.9 times (mean $2 \cdot 3$ ) more ${ }^{3} \mathrm{H}$-glucosamine into macromolecules than non-orchitic testes did. The distribution of incorporated label between the guanidine extract and papain digest was similar to that observed with ${ }^{35} \mathrm{~S}$-sulphate incorporation.

\section{PHYSICAL AND CHEMICAL PROPERTIES OF} RADIOLABELLED MACROMOLECULES

The hydrodynamic distribution of ${ }^{35} \mathrm{~S}$-sulphate, ${ }^{3} \mathrm{H}$-glucosamine, and hexuronic acid in macromolecules found in guanidine extracts of normal and syphilitic rabbit testes was measured using gel filtration (fig 1). The diffusion coefficient (Kav) was calculated using the formula:

$$
\frac{\text { total volume }(\mathrm{Vt}) \text { - eluted volume }(\mathrm{Ve})}{\text { total volume }(\mathrm{Vt}) \text { - void volume }(\mathrm{Vo})}
$$

Extracts of normal rabbit testes did not show appreciable incorporation of ${ }^{35} \mathrm{~S}$-sulphate after

TABLE II Incorporation of ${ }^{3} \mathrm{H}$-glucosamine by orchitic and non-orchitic testes from syphilitic rabbits. (No (\%) disintegrations per minute/mg wet weight)

\begin{tabular}{|c|c|c|c|}
\hline & $\begin{array}{l}\text { Non-orchitic } \\
\text { testes }\end{array}$ & $\begin{array}{l}\text { Orchitic } \\
\text { testes }\end{array}$ & Increase (\%) \\
\hline \multirow{3}{*}{$\begin{array}{l}\text { Rabbit } 4 \\
\text { guanidine } \\
\text { papain } \\
\text { total } \\
\text { Rabbit } 5 \\
\text { guanidine } \\
\text { papain } \\
\text { total } \\
\text { Rabbit } 6 \\
\text { guanidine } \\
\text { papain } \\
\text { total }\end{array}$} & $\begin{array}{rr}91 & (57) \\
61 & (43) \\
157 & (100)\end{array}$ & $\begin{array}{lr}307 & (67) \\
150 & (33) \\
457 & (100)\end{array}$ & 290 \\
\hline & $\begin{array}{rr}265 & (79) \\
67 & (21) \\
332 & (100)\end{array}$ & $\begin{array}{rr}461 & (87) \\
64 & (13) \\
525 & (100)\end{array}$ & 160 \\
\hline & $\begin{array}{rr}246 & (76) \\
77 & (24) \\
323 & (100)\end{array}$ & $\begin{array}{ll}710 & (79) \\
182 & (21) \\
892 & (100)\end{array}$ & 280 \\
\hline $\begin{array}{l}\text { Mean } \\
\text { guanidine } \\
\text { papain } \\
\text { total }\end{array}$ & $\begin{array}{rr}201 & (74) \\
70 & (26) \\
271 & (100)\end{array}$ & $\begin{array}{ll}494 & (79) \\
132 & (21) \\
625 & (100)\end{array}$ & 230 \\
\hline
\end{tabular}



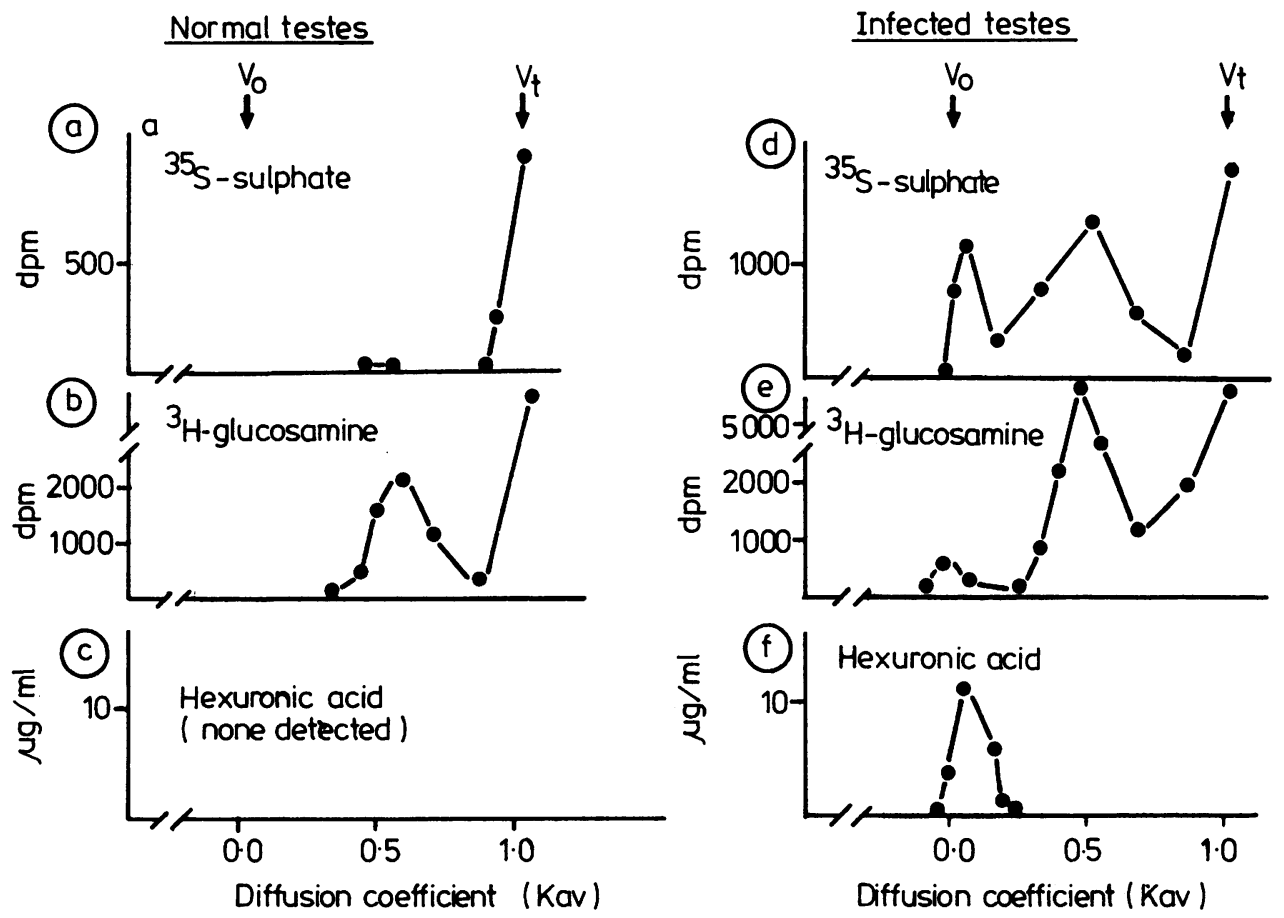

FIG 1 Gel filtration on Sepharose CL-6B of radiolabelled macromolecules from normal ( $a, b$, and c) and infected $(d, e$, and $f)$ testes and elution with buffer containing 4 mol/l guanidine hydrochloride $(a, b, d$, and $e)$ or $0.2 \mathrm{~mol} / \mathrm{l}$ pyridine-acetic acid (c and $f)$. Fractions were assayed for presence of radiolabel $\beta^{35}$ or $\left.{ }^{3} \mathrm{H}\right)$ or hexuronic acid. $(\mathrm{Dpm}=$ disintegrations per minute; Vo = void volume; $V t=$ total volume.)

fractionation on Sepharose CL-6B (fig 1a) and no hexuronic acid was detected (fig 1c). Normal rabbit testes did incorporate ${ }^{3} \mathrm{H}$-glucosamine into fractions with peak Kav of 0.50 (fig $1 \mathrm{~b}$ ).

Extracts of syphilitic orchitic testes radiolabelled with ${ }^{35} \mathrm{~S}$-sulphate contained two peaks with Kav of 0.02 (about $2 \times 10^{6}$ daltons) and $0.50\left(0.05 \times 10^{6}\right.$ daltons) (fig 1d) which were not found in extracts of normal rabbit testes. A similar distribution of labelled macromolecules was seen after gel filtration of guanidine extracts of syphilitic rabbit testes labelled with ${ }^{3} \mathrm{H}$-glucosamine (fig le). The small molecular weight fraction which was present in normal rabbit testes, increased in the guanidine extracts of syphilitic orchitic testes. Hexuronic acid was also present in extracts of syphilitic rabbit testes (fig 1f). The distribution of hexuronic acid on Sepharose CL-6B, from extracts of infected testes showed only one peak, which eluted at the void volume (Vo) and corresponded to the large macro- molecule which incorporated both ${ }^{35} \mathrm{~S}$-sulphate and ${ }^{3} \mathrm{H}$-glucosamine.

These results suggest that at peak syphilitic infection, rabbit testes incorporate ${ }^{35} \mathrm{~S}$-sulphate and ${ }^{3} \mathrm{H}$-glucosamine into two populations of macromolecules not observed in normal rabbit testes. The fraction eluting near the excluded volume of the Sepharose CL-6B column contained hexuronate, which suggested that this fraction may contain a proteoglycan. This was substantiated by the fact that $\beta$-elimination of this macromolecule ${ }^{19}$ resulted in the ${ }^{35}$ S-label eluting on Sepharose CL-6B in the position of glycosaminoglycans (data not shown). The smaller fraction did not contain hexuronate and on $\beta$-elimination the ${ }^{35} \mathrm{~S}$-label eluted on Sepharose CL6B at the included volume of the column (data not shown), which indicated that it was probably a sulphated glycoprotein. That these molecules were sulphated suggested that either or both were polyanions and they may have been responsible for the poly- 
anionic staining seen histologically in sections of testes infected with syphilis.

INCORPORATION OF ${ }^{35}$ S-SULPHATE BY SYPHILITIC RABBIT TESTES TREATED IN VITRO WITH PENICILLIN

To investigate the relation between ${ }^{35} \mathrm{~S}$-sulphate incorperation and viable organisms, slices of rabbit testes infected with $T$ pallidum were incubated in vitro with penicillin for various periods of time before radiolabelling. Samples were inoculated intradermally into the backs of rabbits to assess the efficacy of the antibiotic treatment and the results are shown in fig 2. The latent periods for syphilitic lesions resulting from samples containing penicillin were significantly longer $(p<0.001)$ than those from medium without penicillin. As latent periods of dermal syphilitic lesions are directly related to the number of viable $T$ pallidum organisms injected, ${ }^{2}$ this result indicated that penicillin treatment was succesful in reducing the number of virulent treponemes in the slices of infected testes. After incubation with or without antibiotic for various periods of time, the tissue slices were radiolabelled with ${ }^{35} \mathrm{~S}$-sulphate in fresh medium without antibiotic. The incorporation of ${ }^{35} \mathrm{~S}$-sulphate into macromolecules was measured by gel filtration (fig 3 ).

No correlation was seen between the number of viable $T$ pallidum organisms in the testis tissue and the incorporation of ${ }^{35} \mathrm{~S}$-sulphate into the testis, nor was any appreciable difference found between the incorporation of ${ }^{35} \mathrm{~S}$-sulphate by tissue slices treated with penicillin (for up to 300 minutes) before labelling and those not treated. This result implies that incorporation of ${ }^{35} \mathrm{~S}$-sulphate into macromole-

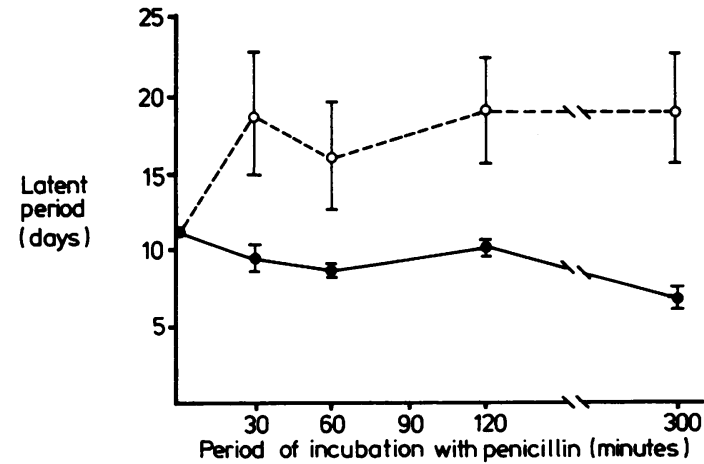

FIG 2 Mean latent periods of syphilitic lesions at three inoculation sites per eluate from infected testes incubated in vitro with (O_— penicillin. Longer latent periods indicate decreased treponemal viability. (Bars represent ranges of latent periods.)

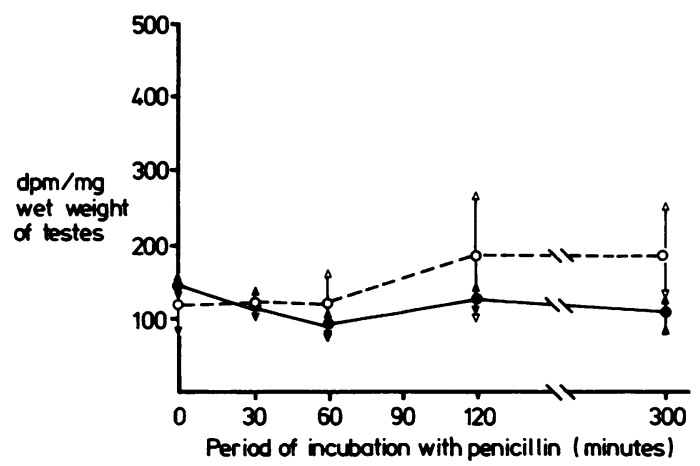

FIG 3 Incorporation of ${ }^{35}$ S-sulphate into macromolecules by tissue slices of infected testes incubated with

$(\mathrm{O} \longrightarrow)$ and without $(\bullet-\bullet)$ penicillin for various periods of time before labelling.

(Dpm = disintegrations per minute.)

cules by syphilitic testes was due to host rather than treponemal biosynthesis.

INCORPORATION OF ${ }^{35}$ S-SULPHATE BY TESTES FROM NORMAL, SYPHILITIC, AND PENICILLIN TREATED RABBITS

To determine the association between ${ }^{35} \mathrm{~S}$-sulphate incorporation by slices of testes and the syphilitic infection process, we measured incorporation of the radiolabel by normal tissue, syphilitic tissue, and tissue from rabbits treated in vivo with $100 \mathrm{mg} / \mathrm{kg}$ penicillin two days before castration and radiolabelling (fig 4). Rabbits were infected with $T$ pallidum in one testis only and developed unilateral orchitis. Tissue from each orchitic and non-orchitic testis was labelled with ${ }^{35} \mathrm{~S}$-sulphate and the tissues compared for incorporation. No motile treponemes were seen on dark field microscopy of samples eluted from testes of rabbits treated with penicillin, although dark field microscopy of undiluted eluates will detect as few as $0.05 \times 10^{6} / \mathrm{ml} T$ pallidum.

Orchitic testes from both untreated and treated syphilitic rabbits incorporated more ${ }^{35} \mathrm{~S}$-sulphate on a wet weight basis than did normal rabbit testes, which indicated that synthesis of the macromolecule containing sulphate could continue even after the death of $T$ pallidum. Incorporation by orchitic testes from syphilitic rabbits treated with penicillin, however, was $70 \%$ (mean) less than that by untreated syphilitic rabbits. This suggests that the large increase in synthesis of sulphated macromolecules by orchitic testes was largely dependent on, but not mediated by, viable treponemes in the tissues. Slices of tissue from non-orchitic testes contralateral to orchitic testes also incorporated more ${ }^{35} \mathrm{~S}$-sulphate than normal rabbit testes did (fig 4). Both the orchitic and non-orchitic 


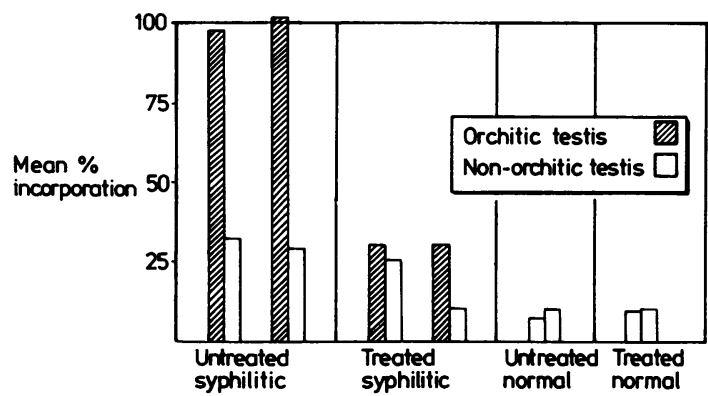

FIG 4 Incorporation of ${ }^{35} \mathrm{~S}$-sulphate by testes from normal, syphilitic, and penicillin treated rabbits.

(Incorporation expressed as mean percentage of that at peak orchitis $(160$ disintegrations per minute

${ }^{35} \mathrm{~S}$-sulphate/mg wet weight of testis arbitrarily designated $100 \%)$ ).

testes of infected rabbits incorporated less ${ }^{35} \mathrm{~S}$-sulphate after treatment in vivo with penicillin. These observations confirm that circulating treponemes established subclinical contralateral orchitis which leads to greater incorporation by non-orchitic syphilitic testes than by normal rabbit testes. In vivo penicillin treatment did not noticeably affect incorporation of ${ }^{35} \mathrm{~S}$-sulphate by normal rabbit testes.

\section{STAINING INFECTED RABBIT TESTES WITH}

\section{ALCIAN BLUE}

Sections were cut from normal rabbit testes, testes from rabbits showing peak syphilitic orchitis, peak orchitic testes treated in vivo with penicillin, and testes from rabbits recovering from syphilitic orchitis were fixed in formalin and embedded in paraffin. Samples of tissue were also removed from each of the testes for silver staining before fixation. Alcian blue, a cationic stain, was used to show the presence of polyanions in each of the sections; it did not stain normal rabbit testes (fig 5a). Sections from testes removed at peak orchitis showed focal staining for polyanions in interstitial areas between seminiferous tubules (fig 5 b) where $T$ pallidum was seen in silver stained sections (photomicrographs not shown). In contrast, sections taken from rabbit testes 3-5 days after peak syphilitic orchitis showed diffuse hyperchromasia (fig 5c), and no treponemes were visible in silver stained sections of these testes (photomicrographs not shown). The tissue in these sections appeared to be undergoing fibrosis. Staining with alcian blue was greatly reduced in sections of orchitic and non-orchitic testes removed from the rabbits treated in vivo with penicillin. The morphology of the testes was well preserved and there was much less fibrosis and cellular infiltration into interstitial

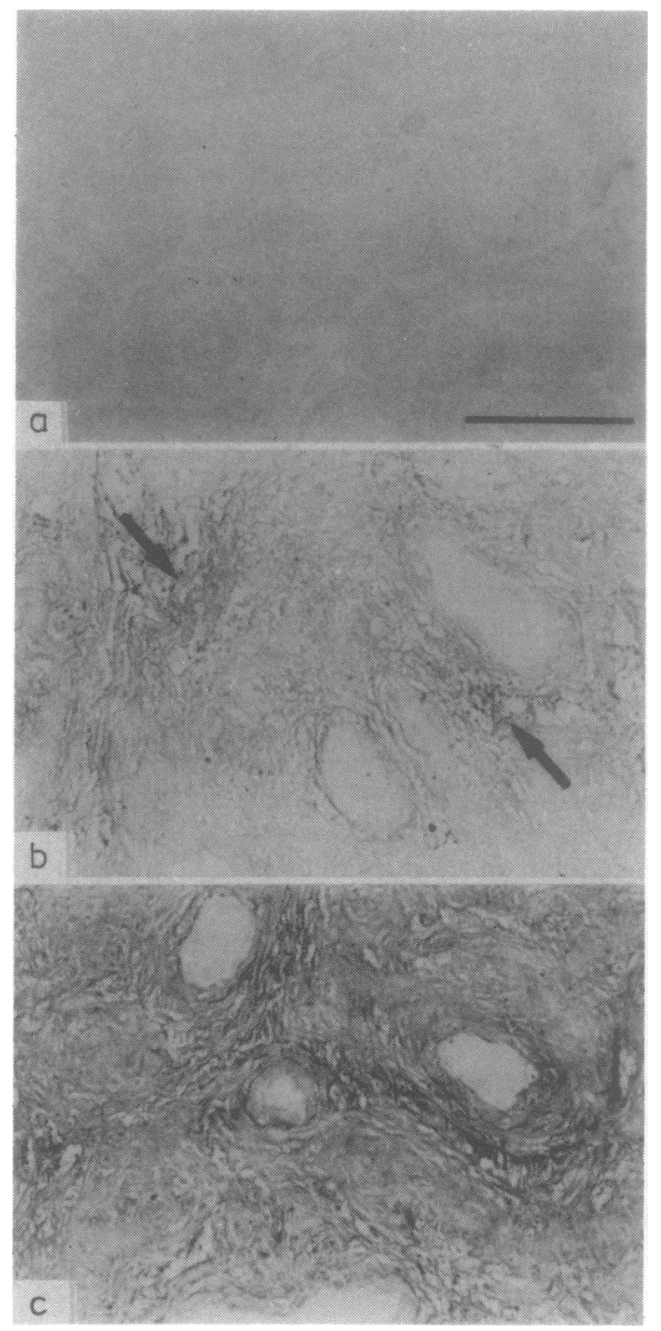

FIG 5 Alcian blue staining of polyanions in sections from a) normal rabbit testis, b) testis at peak orchitis (polyanions at darkly stained focal areas, arrowed), and c) five days after peak orchitis (polyanions diffuse in tissue). Silver stained sections of each tissue showed treponemes at peak orchitis only (photomicrographs not shown). (Bar represents $20 \mu \mathrm{m}$.)

spaces between seminiferous tubules (fig 6a) than in sections of orchitic testes which were untreated (fig 6b).

These results suggested that polyanion synthesis was associated with fibrosis and was maximal after peak orchitis. Penicillin treatment in vivo prevented inflammation and staining with alcian blue and concomitantly reduced the incorporation of ${ }^{35} \mathrm{~S}$-sulphate. 


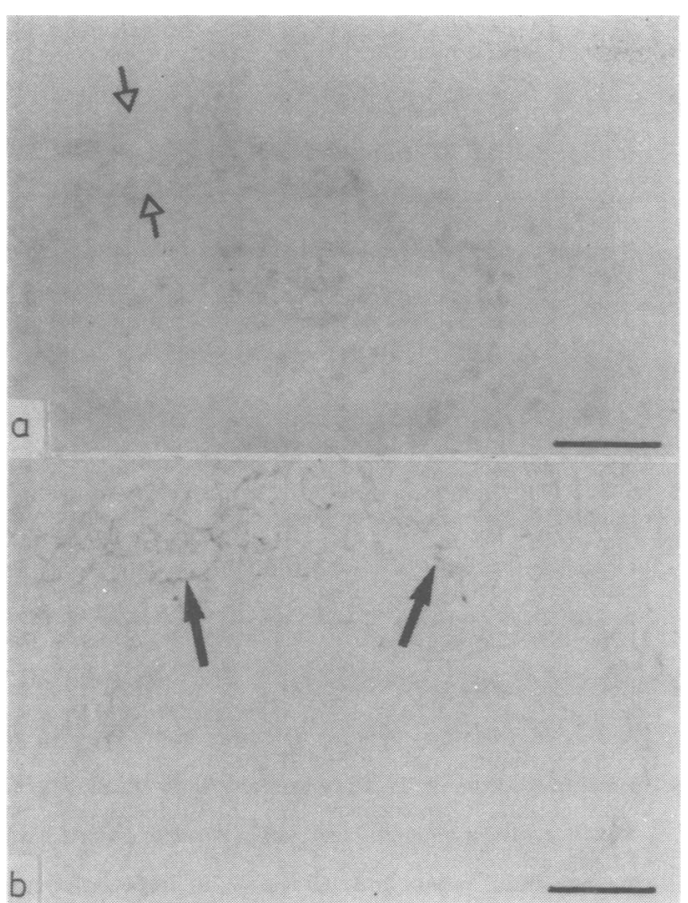

FIG 6 Alcian blue staining of testes from syphylitic rabbits a) treated in vivo with penicillin two days before peak orchitis (slight lymphotytic infiltrate (arrowed) and only small amounts of polyanionic material stained) and b) untreated (greater infiltration, focal amorphous polyanionic material (arrowed) between seminiferous tubules). (Bar represents $5 \mu \mathrm{m}$.)

\section{Discussion}

The pathogenesis of syphilis is poorly understood and it is not known whether the severe disease often associated with tertiary and congenital syphilis is mediated by the treponeme or the host. Until recently no toxic moeity had been associated with $T$ pallidum, but Wong et al found that extracts of syphilitic testes and treponemes were equally toxic. ${ }^{20} T$ pallidum inhibited macromolecular synthesis of tissue culture monolayers in vitro, but it is not known whether this toxicity is active in vivo. Other authors have shown axonal dysfunction following in vitro attachment of $T$ pallidum to cultured neurones. ${ }^{21} 22$

Many of the clinical symptoms of congenital syphilis appear to result from aberrations in connective tissue synthesis, ${ }^{6}$ and histological changes in the ground substance have long been recognised in experimentally infected rabbits. ${ }^{22}$ The normal connective tissue of rabbit testes becomes embryonic in appearance after infection with $T$ pallidum, ${ }^{23}$ and metachromasia (which is removed by treatment with testicular hyaluronidase) is seen on staining with the cationic stain toluidine blue. ${ }^{3}$ This led investigators to postulate that $T$ pallidum synthesised glycosaminoglycans, ${ }^{6}$ which are a component of normal mammalian connective tissue. We have shown that $T$ pallidum does not synthesise these macromolecules in vitro. ${ }^{12}$ Increased amounts of material resembling glycosaminoglycan in syphilitic serum and tissues were recently reported. ${ }^{4}$

In this study, incorporation of ${ }^{35} \mathrm{~S}$-sulphate and ${ }^{3} \mathrm{H}$-glucosamine into macromolecules was increased in orchitic testes. As most of the radiolabelled macromolecules were extracted with guanidine hydrochloride, they were probably either weakly associated with the cells or were in the extracellular matrix of the tissue. The distribution of the labelled macromolecules showed the synthesis of two distinct fractions. The fraction with high molecular weight contained hexuronic acid, which indicated that it might be a proteoglycan, while the fraction with low molecular weight did not contain hexuronate, which suggested that it was a sulphated glycoprotein. These macromolecules were synthesised in amounts that were independent of the number of viable $T$ pallidum organisms present in the testis tissue. This suggests that they were produced by the host rather than by treponemal biosynthesis. Synthesis of the macromolecules, however, was largely dependent on concurrent infection with $T$ pallidum, as treatment with penicillin two days before labelling of tissue greatly reduced incorporation of the radiolabelled precursors. This suggests that $T$ pallidum might stimulate host tissues and in some way cause an increased synthesis of these macromolecules by the host. Such an interaction has been observed in vitro following parasitism of tissue culture monolayers by $T$ pallidum. ${ }^{11}$

Alcian blue staining of rabbit testes at peak syphilitic orchitis showed foci of amorphous polyanionic material. The polyanionic foci were restricted to interstitial areas, where large numbers of $T$ pallidum were found by silver staining. Because of the in situ relation between the polyanionic material and $T$ pallidum, we suggest that these foci may represent deposition of the postulated proteoglycan. Diffuse alcian blue hyperchromasia was observed 3-5 days after peak orchitis, at a time when $T$ pallidum could not be shown histologically. Hyperchromasia was not restricted to interstitial areas, but was a diffuse reaction apparently associated with fibrosis. The role of polyanions in tissue repair has been reported previously. ${ }^{24}$ Treatment of tissue with penicillin reduced both the inflammatory process and polyanion staining with alcian blue.

These results suggest that inflammation caused by $T$ pallidum starts synthesis by the host of both 
proteoglycan and glycoprotein macromolecules. If infection (and inflammation) is arrested by penicillin treatment incorporation of ${ }^{35} \mathrm{~S}$-sulphate and staining of polyanion is reduced; whereas if the infection proceeds inflammation leads to fibrosis and the synthesis of polyanions is greatly increased.

We thank Monash University, the Heiser Foundation, and the National Health and Medical Research Council of Australia for financial help, and Anna Pugliese for the careful typing of this manuscript.

\section{References}

1. Scott V, Dammin GJ. Morphologic and histochemical sequences in syphilitic and in tuberculous orchitis in the rabbit. American Journal of Syphilis, Gonorrhea, and Venereal Disease 1954;38: 189-202.

2. Turner TB, Hollander DH. Biology of the treponematoses. WHO Monogr ser 1957; No 35.

3. Scott V, Dammin GJ. Hyaluronidase and experimental syphilis III. Metachromasia in syphilitic orchitis and its relationship to hyaluronic acid. American Journal of Syphilis, Gonorrhea, and Venereal Disease 1950;34:501-14.

4. Baughn RE, Musher DM. Reappraisal of lymphocyte responsiveness to concanavalin A during experimental syphilis: evidence that glycosaminoglycans in the sera and tissues interfere with active binding sites on the lectin and not with the lymphocytes. Infect Immun 1982; 35: 552-9.

5. Turner TB. Syphilis and the treponematoses. In: Mudd S, ed. Infectious agents and host reactions. Philadelphia: WB Saunders, 1970; 346-90.

6. Fitzgerald TJ. Pathogenesis and immunology of Treponema pallidum. Annu Rev Microbiol 1981;35:29-54.

7. Fitzgerald $T J$, Johnson RC. Influence of testicular fluid infected with Treponema pallidum on intradermal lesions. BrJ Vener Dis 1980;56: 125-8.

8. Bey RF, Johnson RC, Fitzgerald TJ. Suppression of lymphocyte response to concanavalin $A$ by mucopolysaccharide material from Treponema pallidum-infected rabbits. Infect Immun 1979; 26:64-9.
9. Zeigler JA, Jones AM, Jones RH, Kubica KM. Demonstration of extracellular material at the surface of pathogenic $T$ pallidum cells. Br J Vener Dis 1976;52:1-8.

10. Fitzgerald TJ, Cleveland P, Johnson RC, Miller JN, Sykes JA. Scanning electron microscopy of Treponema pallidum (Nichols strain) attached to cultured mammalian cells. $J$ Bacteriol 1977; 130: 1333-44.

11. Fitzgerald TJ, Johnson RC, Wolff ET. Mucopolysaccharide material resulting from the interaction of Treponema pallidum (Nichols strain) with cultured mammalian cells. Infect Immun 1978;22:575-84.

12. Strugnell RA, Handley CJ, Lowther DA, Faine S, Graves SR. Treponema pallidum does not synthesise in vitro a capsule containing glycosaminoglycans or proteoglycans. $\mathrm{Br} J$ Vener Dis 1984;60:8-13.

13. Alderete JF, Baseman JB. Surface associated host proteins on virulent Treponema pallidum. Infect Immun 1979; 26: 1048-56.

14. Bitter T, Muir HM. A modified uronic acid carbazole reaction. Anal Biochem 1962;4:330-4.

15. Turner TB. Protective antibodies in the serum of syphilitic rabbits. J Exp Med 1939;69:867-90.

16. Stevens RL, Nissley SP, Kimura JH, Rechler MM, Caplan AI, Hascall VC. Effects of insulin and multiplication-stimulating activity on proteoglycan biosynthesis in chondrocytes from the Swarm rat chondrosarcoma. J Biol Chem 1981;256:2045-52.

17. Drury RAB, Wallington EA. Carleton's Histological Techniques. 4th ed. New York: Oxford University Press, 1967.

18. Roden L, Schwartz N. Biosynthesis of connective tissue proteoglycans. In: Whelan WJ, ed, MTP International Review of Science (Biochemistry Series 1) Biochemistry of Carbohydrates London: Butterworths, 1975;5:95-182.

19. Hascall VC, Kimura JH. Proteoglycans: isolation and characterization. In: Cunningham LW, Frederiksen DW, eds. Methods in Enzymology New York: Academic Press, 1982; 82: 769-800.

20. Wong GHW, Steiner BM, Graves S. Inhibition of macromolecular synthesis in cultured rabbit cells by Treponema pallidum. Infect Immun 1983;41:636-43.

21. Oakes SG, Repesh LA, Pozos RS, Fitzgerald TJ. Electrophysical dysfunction and cellular disruption of sensory neurones during incubation with Treponema pallidum. $\mathrm{Br} J$ Vener Dis 1982;58:220-7.

22. Repesh LA, Fitzgerald TJ, Oakes S, Pozos RS. Scanning electron microscopy of the attachment of Treponema pallidum to nerve cells in vitro. $\mathrm{Br} J$ Vener Dis 1982;58:211-9.

23. Scott V, Dammin GJ. Experimental syphilis in the rabbit: the relationship of metachromasia to fibrinoid degeneration of collagen and the localization of spirochetes in the testis. $J \mathbf{L a b}$ Clin Med 1949;34: 1748-9.

24. Shoshan S. Wound Healing. Int Rev Connect Tissue Res 1982; 9:1-26. 